\title{
The role of the Brr5/Ysh1 C-terminal domain and its homolog Syc1 in mRNA $3^{\prime}$-end processing in Saccharomyces cerevisiae
}

\author{
ALEXANDER ZHELKOVSKY, ${ }^{1}$ YOKO TACAHASHI, ${ }^{1}$ TOMMY NASSER, ${ }^{3}$ XIAOYUAN HE, ${ }^{1}$ \\ ULRIKE STERZER, ${ }^{2}$ TORBEN HEICK JENSEN, ${ }^{3}$ HORST DOMDEY, ${ }^{2,4}$ and CLAIRE MOORE ${ }^{1}$ \\ ${ }^{1}$ Department of Molecular Microbiology, Tufts University School of Medicine and the Sackler School of Graduate Biomedical \\ Sciences, Boston, Massachusetts 02111, USA \\ ${ }^{2}$ Institut fur Biochemie, Universitat Munchen, Munich, D-81375, Germany \\ ${ }^{3}$ Department of Molecular Biology, Aarhus University, Aarhus, 8000, Denmark
}

\begin{abstract}
The cleavage/polyadenylation factor (CPF) of Saccharomyces cerevisiae is thought to provide the catalytic activities of the mRNA 3 '-end processing machinery, which include endonucleolytic cleavage at the poly(A) site, followed by synthesis of an adenosine polymer onto the new $3^{\prime}$-end by the CPF subunit Pap1. Because of similarity to other nucleases in the metallo- $\beta$ lactamase family, the Brr5/Ysh1 subunit has been proposed to be the endonuclease. The C-terminal domain of Brr5 lies outside of $\beta$-lactamase homology, and its function has not been elucidated. We show here that this region of Brr 5 is necessary for cell viability and mRNA 3'-end processing. It is highly homologous to another CPF subunit, Syc1. Syc1 is not essential, but its removal improves the growth of other processing mutants at restrictive temperatures and restores in vitro processing activity to cleavage/ polyadenylation-defective brr5-1 extract. Our findings suggest that Syc1, by mimicking the essential Brr5 C-terminus, serves as a negative regulator of mRNA 3 '-end formation.
\end{abstract}

Keywords: mRNA 3'-end processing; polyadenylation

\section{INTRODUCTION}

Production of functional eukaryotic mRNA requires the addition of a poly(A) tail at the $3^{\prime}$-end by a large complex whose composition is well-conserved from yeast to mammals. This nuclear $3^{\prime}$-end processing machinery recognizes signal sequences on the precursor RNA that specify the poly(A) site, cuts the RNA at this site, and synthesizes a polyadenosine tract onto the new $3^{\prime}$-end. In the yeast Saccharomyces cerevisiae, the cleavage/polyadenylation factor $(\mathrm{CPF})$ works in conjunction with a second multi-subunit factor, CF I, to process the $3^{\prime}$-ends of mRNA precursor.

The catalytic subunit responsible for poly(A) addition, the Pap1 poly(A) polymerase, is a subunit of CPF. Recently, comparative protein sequence analysis has suggested that a second CPF component, Brr5/Ysh1 (Chanfreau et al. 1996;

\footnotetext{
${ }^{4}$ Present address: Bio ${ }^{\mathrm{M}}$ AG Munich Bio Tech Development, Martinsried, 82152, Germany.

Reprint requests to: Claire Moore, Department of Molecular Microbiology, Tufts University School of Medicine, Boston, MA 02111, USA; e-mail: Claire.moore@tufts.edu; fax: (617) 636-0337.

Article published online ahead of print. Article and publication date are at http://www.rnajournal.org/cgi/doi/10.1261/rna.2267606.
}

Jenny et al. 1996), might be the nuclease. This protein and its mammalian homolog, CPSF-73, belong to a large family of metallo-hydrolytic enzymes with motifs resembling those forming the active-site fold of $\beta$-lactamases (Aravind 1999; Daiyasu et al. 2001; Callebaut et al. 2002). This family contains three proteins with demonstrated nuclease activity: a V(D)J DNA recombination/repair factor called Artemis (Ma et al. 2002), the Snm1 protein involved in DNA cross-link repair ( $\mathrm{Li}$ et al. 2005), and RNase Z, an endonuclease that trims the $3^{\prime}$-ends of tRNA precursors (Schiffer et al. 2002). A study by Ryan et al. (2004) showed that highly conserved residues in the region of Brr5/Ysh1 with $\beta$-lactamase homology are essential for cell growth and that a protein with the properties of CPSF-73 could be crosslinked to the cleavage site of mammalian mRNA precursor. CPSF-73 has recently been implicated in the processing of metazoan histone mRNA transcripts, which are cleaved but not polyadenylated (Dominski et al. 2005; Kolev and Steitz 2005). These findings support the notion that the endonuclease is Brr5/Ysh1 and its homolog CPSF-73, although direct proof of nuclease activity is still lacking.

Affinity purification revealed another interesting feature of the CPF complex related to Brr5/Ysh1-its C-terminus is 
duplicated as a nonessential subunit of CPF called Syc1 (Gavin et al. 2002; He et al. 2003; Nedea et al. 2003). The function of the C-terminus of Brr5/Ysh1 and of Syc1 is not known. In this study, we show that this domain of Brr5/ Ysh1 is critical for cell survival, and is needed for both steps of $3^{\prime}$-end processing. Finally, even though Sycl is not essential, its presence exacerbates the processing and growth defects of several processing mutants, suggesting a role for Syc1 in modulating the efficiency of $3^{\prime}$-end processing.

\section{RESULTS}

The C-terminus of Brr5/Ysh1 starting at amino acid 582 exhibits a striking conservation ( $38 \%$ identity) with amino acids $28-188$ of Syc1, a $21-\mathrm{kDa}$ protein of 188 amino acids that copurifies with CPF (Gavin et al. 2002; He et al. 2003; Nedea et al. 2003) (Fig. 1A,B). Figure 1A also depicts the metallo- $\beta$-lactamase domain of Brr5/Ysh1 in relationship to this $\mathrm{C}$-terminal domain. The first 500 amino acids of Brr5 exhibit the greatest similarity to its mammalian homo$\log$, CPSF-73, and contain the region common to proteins in the $\beta$-CASP subfamily whose characterized members act on nucleic acids (Callebaut et al. 2002).

\section{The C-terminal region of Brr5 is essential for cell viability}

The C-terminus of Brr5 contains two potential motifs suggestive of function-a leucine zipper, which mediates protein/protein interactions, and a P-loop motif (Saraste et al. 1990) of $\mathrm{GX}_{4-8} \mathrm{GKS} / \mathrm{T}$, found in proteins that bind ATP or GTP (Fig. 1B). While deletion of the last 30 amino acids of $\operatorname{Brr} 5(\Delta \mathrm{C} 30)$ is lethal, smaller truncations of 19 or 10 amino acids (Fig. 1C, $\Delta \mathrm{C} 19$ and $\Delta \mathrm{C} 10$ ) do not affect cell viability or cause cold- or heat-sensitive growth (data not shown). Thus, if this region is a leucine zipper, it does not mediate an interaction critical for Brr5 function. Overexpression of Syc1, or deletion of the SYC1 gene, cannot rescue the lethality of $\Delta \mathrm{C} 30 \mathrm{Brr} 5$ (data not shown). However, consistent with the high degree of conservation, the C-terminal sequence of Brr5 can be replaced with homologous Sycl sequence without affecting cell viability or growth rate (Fig. 1C).

Several studies have shown that ATP is important for the cleavage step in the processing of yeast mRNA precursor (Butler and Platt 1988; Chen and Moore 1992; Zhao et al. 1997). To investigate whether the P-loop motif in the Brr5 C-terminus might be involved in the ATP requirement, we made the amino acid replacements K740D or K740H. These substitutions have no effect on cell growth, but a different replacement, T737V, is lethal (Fig. 1C). This amino acid is conserved between Brr5 and Syc1, and while it immediately precedes the GKS of the putative P-loop, it is not part of the P-loop consensus. The inviability of the T737V and brr5$\Delta \mathrm{C} 30$ mutants shows that this region of Brr5 is important for activity, while the neutral effect of the point mutations
A

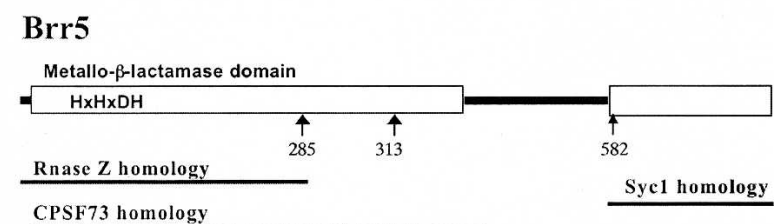$$
\text { Cft2 homology }
$$

B

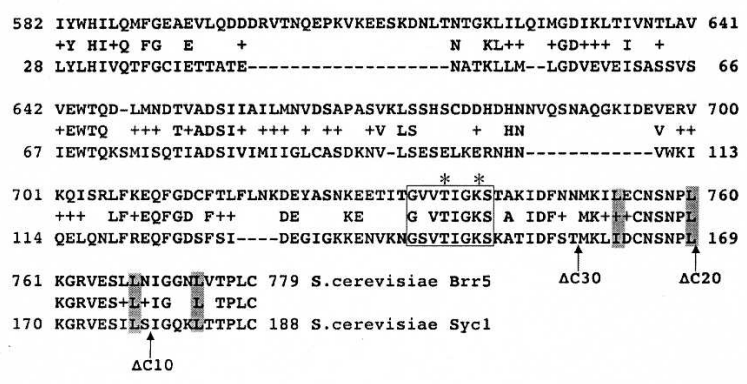

C

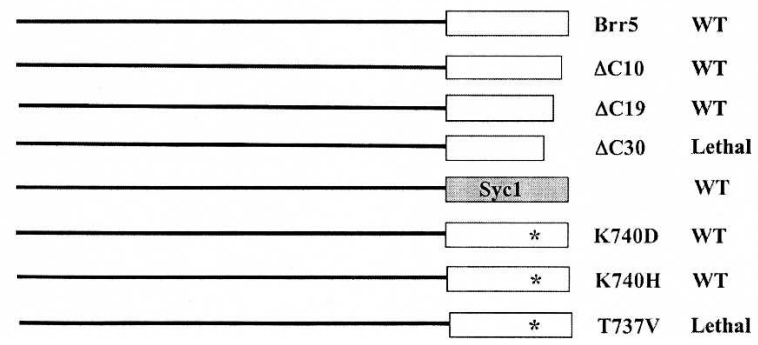

FIGURE 1. Mutagenesis reveals the critical nature of the Brr5 Cterminal domain. (A) Schematic of the region of Brr5 that places it in the metallo- $\beta$-lactamase family and the region homologous to the CPF Sycl subunit. (B) Alignment of Sycl amino acids 28-188 with the Brr5 C-terminus beginning at amino acid 582. The putative P-loop motif is boxed, and amino acids T737 and K740 within this motif that were targeted for mutagenesis are marked by an asterisk. A possible leucine-rich motif is marked by shaded amino acids. Identical amino acids are noted, and similar amino acids are indicated by a.$+(C)$ Mutational analysis of the Brr5 C-terminus. The indicated mutations were made in BRR5 and tested for their ability to rescue lethality caused by deletion of the chromosomal BRR5 gene. Growth after forcing loss of a BRR5 covering plasmid on $5^{\prime} \mathrm{FOA}$-containing media is shown on the right. (WT) Indicates growth at $16^{\circ} \mathrm{C}, 25^{\circ} \mathrm{C}$, and $37^{\circ} \mathrm{C}$ that is identical to that of the isogenic wild-type strain; (Lethal) No growth.

at K740 indicates that it does not function to bind ATP or GTP. Brr5 has a second match to the P-loop motif in the Nterminus at positions $31-33$, but mutations of G31A or $\mathrm{K} 32 \mathrm{R}$ in this putative motif also have no effects on cell viability (data not shown).

\section{The C-terminal region of Brr5 is critical for both steps of processing}

Because of the lethality of mutations in the C-terminus of Brr5, it is difficult to ascertain the function of this domain in mRNA 3 '-end processing. To investigate the behavior of Brr5 lacking the $\mathrm{C}$-terminus, we created a strain in which a 
degron tag (Dohmen et al. 1994) was fused to the Nterminus of the chromosomal copy of the BRR5 gene. Consistent with BRR5 being an essential gene, the Degron-brr5 cells die if maintained at $37^{\circ} \mathrm{C}$ (Fig. 2A). When these cells are grown at $24^{\circ} \mathrm{C}$, the Degron-brr5 is expressed at a level comparable to Brr5 in the parental strain, as determined from Western blot analysis using a Brr5-specific antibody (Fig. 2B, lanes 2,4). When cells are shifted to growth at $37^{\circ} \mathrm{C}$, the Degron-brr5 protein is degraded by $90 \mathrm{~min}$, while the level of Brr5 in the wildtype parental strain remains the same (Fig. 2B, lanes 3,5). The levels of several other subunits of CPF (Cft1/Yhh1, Cft2/Ydh1, Pta1, Fip1, and Yth1) were examined and did not change upon Degron-brr5 depletion (data not shown).

We next transformed the Degron-brr5 strain with a plasmid expressing either BRR5 or the brr5- $\triangle C 30$ mutant, and confirmed that the brr5- $\triangle C 30$ mutant could not support growth on its own (Fig. 2A). By Western blot, the wild-type and brr5- $\Delta \mathrm{C} 30$ proteins are stably expressed in this strain at both $24^{\circ} \mathrm{C}$ and $37^{\circ} \mathrm{C}$ (Fig. 2B, lanes 6-9). The activity of processing extracts made from these different strains after depletion of the Degron-Brr5 protein was examined by a cleavage assay using precursor containing the GAL7 poly(A) site and flanking sequences and in the presence of dATP to block poly(A) addition (Fig. 2C), or a poly(A) addition assay using ATP and substrate that terminates at the poly(A) site (Fig. 2D). For these experiments, cells were grown at $24^{\circ} \mathrm{C}$, and the cultures were split, with half continuing to grow at $24^{\circ} \mathrm{C}$ and the other half shifted to $37^{\circ} \mathrm{C}$. After $90 \mathrm{~min}$, cultures were harvested for extract preparation. Equal amounts of protein were used in each assay. There was little difference in the processing activity of extracts from the wild-type parental cells grown at $24^{\circ} \mathrm{C}$ or $37^{\circ} \mathrm{C}$ (Fig. $2 \mathrm{~B}, \mathrm{C}$, lanes 2,3 ), indicating that the activity of extracts from the same cells cultured at the two different temperatures could be compared.

Extract prepared from Degron-brr5 cells grown at $24^{\circ} \mathrm{C}$ is consistently defective for processing in vitro compared to the parental wild-type strain (Fig. 2C,D, lanes 2,4). This observation suggests that even though there is no difference
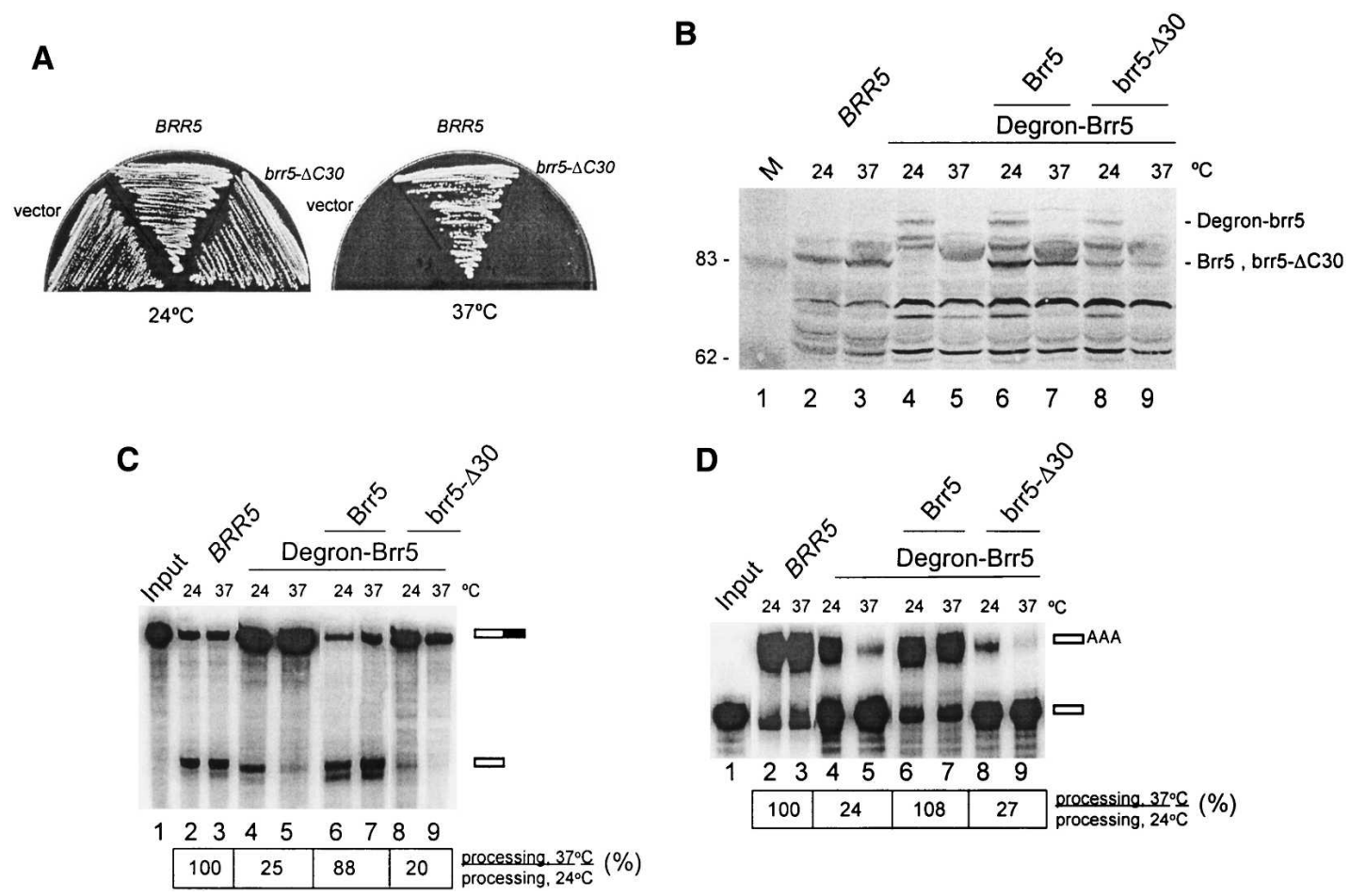

FIGURE 2. The effects of brr 5 mutants on cell growth and mRNA $3^{\prime}$-end processing. (A) The Degron-brr5 strain, or the Degron-brr5 strain with plasmids expressing wild-type Brr5 or brr5- $\Delta \mathrm{C} 30$ mutant proteins, were grown at $24^{\circ} \mathrm{C}$ or shifted to growth at $37^{\circ} \mathrm{C}$. The lethality of degronmediated Brr5 depletion can be prevented by expression of wild-type Brr5 but not brr5- $\Delta \mathrm{C} 30$. (B) The presence of wild-type Brr5, Degron-brr5, or the brr5- $\Delta$ C30 mutant protein was detected by Western blot with Brr5-specific antibody. Extract was prepared from the indicated cells grown at $24^{\circ} \mathrm{C}$ or shifted to growth at $37^{\circ} \mathrm{C}$ for 90 min to remove the Degron-Brr5 protein. The positions of the different forms of Brr5 are indicated on the right. $(C)$ The extracts described in $B$ were examined for cleavage activity using reactions containing radioactive GAL7 precursor and 2'-dATP to block the poly(A) addition step, as described in Materials and Methods. Reaction products were resolved on a $6 \%$ polyacrylamide gel containing 8 $\mathrm{M}$ urea and visualized by PhosphorImager analysis. $(D)$ Activity of the same extracts used in $C$ in a poly(A) addition assay containing ATP and GAL7 substrate that ends at the poly(A) site. Products were analyzed as described for $C$. The positions of unreacted substrate and products are indicated on the right side of $C$ and $D$. (Note that the downstream cleavage product is rapidly degraded and not detectable on these gels.) The efficiency of processing for each strain at $37^{\circ} \mathrm{C}$ relative to that at $24^{\circ} \mathrm{C}$ (using the amount of processing at $24^{\circ} \mathrm{C}$ as $100 \%$ for each pair) is shown under each pair of lanes and represents the average of three separate experiments. 
in growth at this temperature or in the expression level of the Degron-brr5 compared to wild-type cells, the degron tag has compromised Brr5 function. Removal of Degronbrr5 at $37^{\circ} \mathrm{C}$ further impairs cleavage and poly(A) addition to about one-quarter of that seen in the same cells at $24^{\circ} \mathrm{C}$ (Fig. 2C,D, lanes 4,5). While we do not know the reason for the residual activity at $37^{\circ} \mathrm{C}$, it is most likely due to a small amount of Degron-brr5 or partial degradation products remaining in the cells after a shift to $37^{\circ} \mathrm{C}$ for $90 \mathrm{~min}$ (Fig. 2B, lanes 4,5).

Activity in extract from the Degron-Brr5 strain is rescued to wild-type levels at both temperatures by expression of Brr5 from a plasmid-borne gene (Fig. 2C,D, lanes 6,7). These results confirm previous studies implicating Brr5 as a protein needed for both steps of mRNA $3^{\prime}$-end formation (Chanfreau et al. 1996; Jenny et al. 1996; Zhao et al. 1999b). When the brr5- $\Delta \mathrm{C} 30$ mutant is expressed in the Degronbrr5 strain, there is no rescue of activity in extract from cells grown at $24^{\circ} \mathrm{C}$, as there was with expression of wild-type Brr5 (Fig. 2B,C, cf. lanes 6 and 8). Furthermore, depletion of the Degron-brr5 protein in cells expressing brr5- $\Delta \mathrm{C} 30$ caused a marked decline in the efficiency of cleavage and poly(A) addition at $37^{\circ} \mathrm{C}$ to a level comparable to that seen with Degron-brr5 alone (Fig. 2B,C, cf. lanes 8 and 9). In extracts prepared from the Degron-brr5 cells, the efficiency of both the cleavage and poly(A) addition reactions at $37^{\circ} \mathrm{C}$ was fourfold less than it was at $24^{\circ} \mathrm{C}$. In Degron-brr5 cells supplemented with brr5- $\Delta \mathrm{C} 30$, there was a fivefold decrease for cleavage and a 3.7-fold decrease for poly(A) addition. From these data, we conclude that brr5- $\Delta \mathrm{C} 30$ is nonfunctional and that the Brr5 C-terminus is critical for both steps of processing.

To determine if the brr5- $\Delta \mathrm{C} 30$ mutant was incorporated into $\mathrm{CPF}$, we immunoprecipitated Brr5 proteins from wild or mutant extract (after depletion of Degron-Brr5) using Brr5-specific antibody and examined the precipitate by Western blot for the CPF subunits Cft1, Pta1, Pap1, Yth1, and Ssu72. Similar amounts of protein were pulled down with both wild-type and brr5- $\Delta \mathrm{C} 30$ mutant proteins (data not shown), suggesting that the processing defect of brr5$\triangle \mathrm{C} 30$ is not due to loss of the protein from CPF.

\section{The C-terminus of Brr5 interacts with Pta1}

When we conducted a two-hybrid screen for proteins that interacted with full-length Ptal as bait, we identified four strongly scoring clones containing the C-terminus of Brr5 (data not shown). The shortest fusion protein that gave a robust two-hybrid signal contained only amino acids 546779 of Brr5, which is only slightly larger than the region of Brr5 homologous to Syc1. In agreement with this result, GST-Ptal interacts well in a pull-down assay with both Brr5 and its C-terminal homolog Sycl, but not with the Rna15 subunit of CF I (Fig. 3). Thus, the function of this domain of Brr5 may be closely connected to its interaction with Ptal.

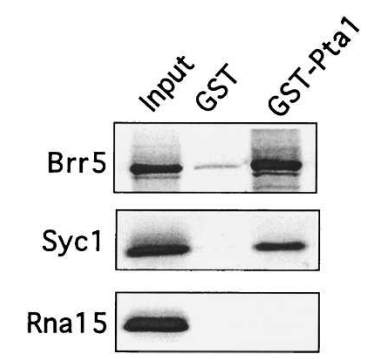

FIGURE 3. GST pull-down assays. Brr5, Syc1, or Rna15 was radioactively labeled by in vitro translation and then incubated with GST or GST-Ptal, and complexes were isolated and analyzed as described in Materials and Methods. GST-Pta1 interacts with Brr5 and Syc1, but not with the Rna15 subunit of CF I. Ten percent of the in vitro translated input is shown.

\section{Deletion of SYC1 affects the viability of many mRNA 3 '-end processing mutants}

The strong homology to the essential Brr5 C-terminus and the association of Sycl with CPF suggests that Syc1 is involved in either the processing event itself or in coordinating $3^{\prime}$-end processing with other steps in mRNA synthesis. However, deletion of the SYC1 gene caused no defect in growth of $S$. cerevisiae on rich media at $25^{\circ} \mathrm{C}, 30^{\circ} \mathrm{C}$, or $37^{\circ} \mathrm{C}$ (Nedea et al. 2003; data not shown). In addition, yeast lacking SYC1 could grow as well as wild-type cells on other carbon sources such as galactose, glycerol, or ethanol, and did not show any increased sensitivity to ultraviolet light or treatment with methyl-methanesulfonate (data not shown).

To probe for a possible function for $S y c 1$, we paired sycl $\Delta$ with mutations in other genes needed for both cleavage and polyadenylation (BRR5, PTA1, PFS2, RNA14, and $R N A 15)$, or for only the polyadenylation step (PAP1 and FIP1). This analysis revealed numerous genetic interactions. For example, syc1 $\Delta$ rescues the thermosensitive (ts) but not the cold-sensitive (cs) phenotype of brr5-1 (Fig. 4A). The deletion of SYC1 also suppresses the lethality of the pta1-2 mutant at $37^{\circ} \mathrm{C}$ (Fig. 4B), but is synthetic lethal with pta1-3 at $24^{\circ} \mathrm{C}$ (Fig. 4C). The following interactions with other $\mathrm{CPF}$ mutants were also observed (Fig. 4D): (1) sycl $\Delta$ enhances the ts and cs growth defect of $p f s 2-1$; (2) $s y c 1 \Delta$ enhances the cs growth defect of fip1-206, but does not affect the ts growth; and (3) $s y c 1 \Delta$ has no effect on the growth of pap1-1. Suppression of growth defects were also observed with mutations in CF I components- $s y c 1 \Delta$ rescues rna14-3 at $34^{\circ} \mathrm{C}$ and rna15-2 at $33^{\circ} \mathrm{C}$, but not at $37^{\circ} \mathrm{C}$ (Fig. 4E; data not shown).

\section{Deletion of the SYC1 gene alleviates the in vitro processing defect of the brr5-1 mutant}

The brr5-1 mutant strain was isolated by Chanfreau et al. (1996) and shown to be cold-sensitive. We have found that it is also thermosensitive and grows very slowly at $37^{\circ} \mathrm{C}$ (Fig. 4A). Extract from the brr5-1 mutant is deficient in 
A
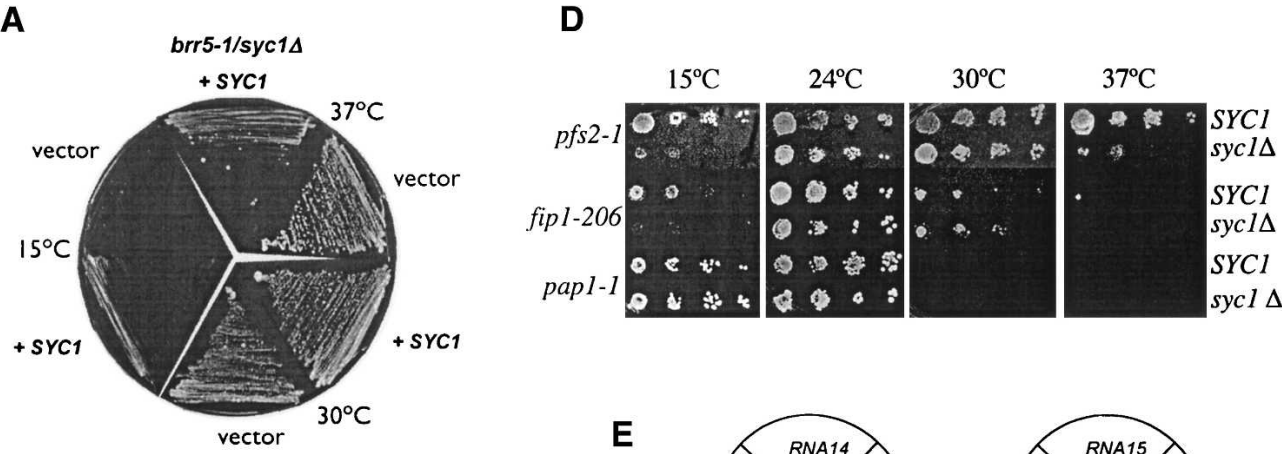

B

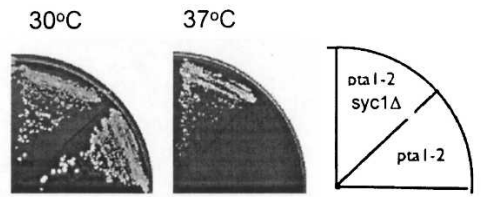

E
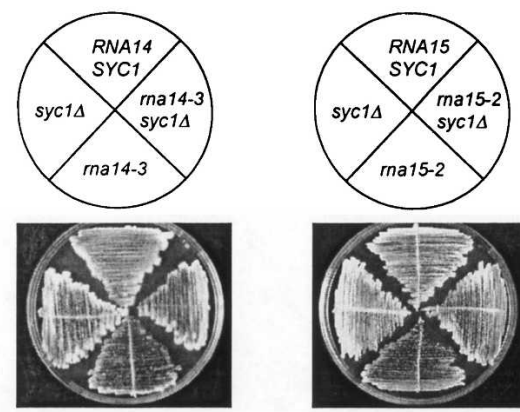

C

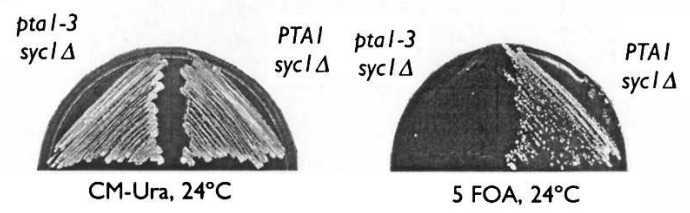

$25^{\circ} \mathrm{C}$

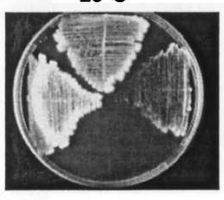

$34^{\circ} \mathrm{C}$

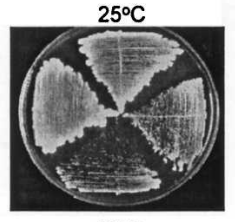

$32^{\circ} \mathrm{C}$

FIGURE 4. Genetic interactions of $s y c 1 \Delta$ with mutations in cleavage/polyadenylation factors. (A) Deletion of SYC1 suppresses the ts growth of the brr5-1 mutant. A haploid strain containing the brr5-1 and sycl $\Delta$ alleles was transformed with vector or plasmid bearing the SYC1 gene, and incubated at the indicated temperatures. (B) Deletion of SYC1 suppresses the ts growth defect of the pta1-2 mutant. (C) Deletion of SYC1 is

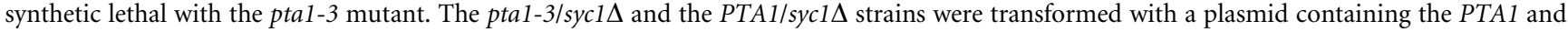
URA3 genes, and grown at $24^{\circ} \mathrm{C}$ on complete media lacking uracil, or in the presence of 5-FOA to remove the plasmid. (D) The syc1 $\Delta$ allele affects the growth of strains containing the $p f s 2-1$ and fip1-206 mutations, but not that of pap1-1. The growth of the $p f s 2-1$, fip1-206, and pap1-1 mutants is shown at different temperatures in the presence or absence of SYC1. (E) The growth of the rna14-3 and rna15-2 mutants is shown at different temperatures in the presence or absence of SYC1. Deletion of SYC1 allows rna14-3 to grow at $34^{\circ} \mathrm{C}$, and improves the growth of $r n a 15-2$ at $32^{\circ} \mathrm{C}$.

poly(A) addition at $15^{\circ} \mathrm{C}($ Chanfreau et al. 1996) and defective for cleavage and poly(A) addition at $30^{\circ} \mathrm{C}$ (Zhao et al. 1999b). By DNA sequencing, we have mapped the mutation in brr5-1 to a single amino acid change (A407T) in the $\beta$-CASP B-motif, indicating that this region of Brr5 has a role in both steps of mRNA $3^{\prime}$-end formation.

The genetic interactions of $s y c 1 \Delta$ with several $3^{\prime}$-end processing mutants suggest that even though Sycl is not essential, it might negatively influence the efficiency of the cleavage/polyadenylation complex. If this hypothesis is correct, sycl $\Delta$ might rescue the thermosensitive growth defect of brr5-1 by relieving the mRNA 3 '-end-processing defect of this mutant. As seen in Figure 5, A and B (lanes $1,2)$, deletion of $S Y C 1$ by itself has no affect on mRNA cleavage and poly(A) addition in vitro. In agreement with Zhao et al. (1999b), extract from the brr5-1 strain is not very active in either step of $3^{\prime}$-end processing (Fig. 5A,B, lane 3). However, when this mutant is paired with $s y c 1 \Delta$, cleavage activity is restored (Fig. 5A, lane 4). Poly(A) addition is partially rescued, with substrate processed at an efficiency almost reaching wild-type levels, but receiving shorter tails than normal (Fig. 5B, lane 4). This observation suggests that poly(A) addition is either less processive in the $\operatorname{brr} 5-1 / s y c 1 \Delta$ extract, or is terminating prematurely.

Many studies have now shown that efficient termination of RNAP II transcription downstream of a poly(A) site requires a functional mRNA $3^{\prime}$-end-processing machinery. This coupling is reflected in the finding that some, but not all yeast mutants that are defective in cleavage also cause defects in transcription termination (Birse et al. 1998; Dichtl et al. 2002a,b; He et al. 2003; Sadowski et al. 2003). As shown in Figure 5A, the brr5-1 mutant is compromised for cleavage activity. To test whether this defect is also associated with difficulty in efficient transcription termination, we used a transcription run-on (TRO) assay developed by Steinmetz and Brow (2003), in which the level of transcription extending through two G-less cassettes of different sizes is measured directly after T1 RNase treatment and denaturing gel electrophoresis (Fig. 5C). 
A

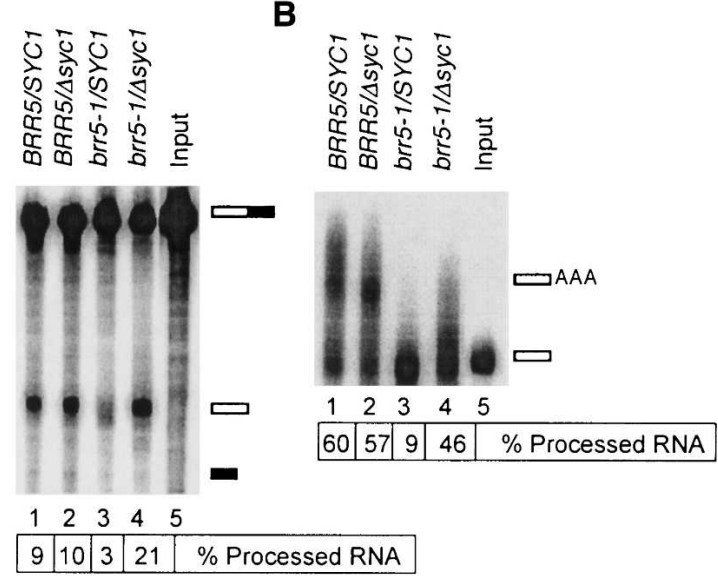

C

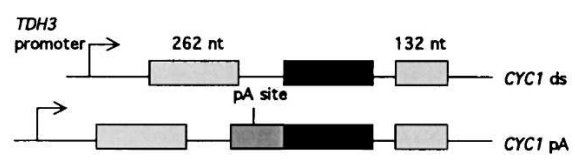

D

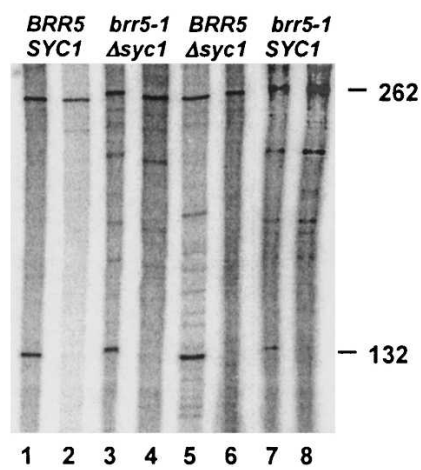

FIGURE 5. Effects of $s y c 1 \Delta$ on mRNA 3 '-end processing activity in vitro. Processing extracts were prepared from the BRR5/SYC1 (wild-type), $B R R 5 / s y c 1 \Delta$, brr5-1/SYC1, and brr5-1/sycl $\Delta$ strains grown at $24^{\circ} \mathrm{C}$ and analyzed for activity as described in Figure 2 . The percentage of processed RNA is indicated under each lane. The Input lanes contain unreacted RNA substrate. $(A)$ Cleavage assay. (B) Poly(A) addition. (C) Diagram of tandem G-less cassette constructs used for transcription run-on (TRO) assays, as described by Steinmetz and Brow (2003). An inert spacer sequence (black rectangle) from a region downstream of the CYC1 poly(A) site, beginning at nucleotide 587 relative to the first nucleotide of the CYC1 open reading frame, is inserted between the two G-less cassettes. The G-less cassettes (light gray) and the CYC1 polyadenylation signal (dark gray) are also indicated. (D) Transcription termination downstream of the CYC1 poly(A) site, as assayed by TRO analysis, is not affected by the brr5-1 or syc1 $1 \Delta$ alleles, alone or in combination. Wild-type (BRR5/SYC1), brr5-1/syc1 $\Delta, B R R 5 /$ syc $1 \Delta$, and brr5-1/SYC1 cells were transformed with the $C Y C 1$ ds (lanes $1,3,5,7$ ) or the $C Y C 1 \mathrm{pA}$ (lanes 2,4,6,8) reporter plasmids were grown at $25^{\circ} \mathrm{C}$ and then shifted to $37^{\circ} \mathrm{C}$ for 90 min before harvesting for the TRO procedure. Loss of the 132-nt fragment with the CYC1 pA construct indicates efficient transcription termination.

Inserting elements that direct $3^{\prime}$-end formation between the two G-less cassettes causes transcription termination to occur before the downstream cassette is transcribed. With this assay, the efficiency of transcription termination can be determined by comparing the amount of radioactivity incorporated into the 262-nt upstream product and the 132-nt downstream product (Fig. 5D). The 132nt fragment does not accumulate when a wild-type strain or strains with the brr5-1 and sycl $1 \Delta$ alleles are incubated at $37^{\circ} \mathrm{C}$ for $90 \mathrm{~min}$ and assayed for transcription through the CYC1 poly(A) site (Fig. 5E, lanes 2,4,6,8). This result indicates that brr5-1 and $s y c 1 \Delta$ mutations do not cause a termination defect.

\section{DISCUSSION}

In this study, we investigated the function of the Cterminal domain of the Brr5 subunit of the yeast cleavage/ polyadenylation factor, CPF, and its homolog Sycl in the $3^{\prime}$-end processing of eukaryotic mRNA. We have found that the C-terminus of Brr5 is essential for both cleavage and poly(A) addition of mRNA precursor. However, the function of this domain does not require the putative leucine-zipper or P-loop motifs present in this part of Brr5. Moreover, the Syc1 protein sequence can substitute for the Brr5 C-terminus when it is part of Brr5 but not when expressed separately.

\section{Putative P-loops in Brr5 are not important for function}

The original studies demonstrating mRNA 3 '-end processing in vitro found that ATP was needed for the cleavage steps, as well as for poly(A) synthesis (Zhao et al. 1999a). This requirement was maintained even upon purification of the processing factors. In these studies, creatine phosphate was included in the reactions for the purpose of regenerating ATP. Manley and colleagues have shown that creatine phosphate was sufficient, and moreover, could be replaced in the cleavage reaction by the C-terminal domain (CTD) of RNA polymerase II (RNAP II) in the mammalian system (Hirose and Manley 1998; Ryan et al. 2002). These findings correlated well with numerous other studies showing that the efficiency and specificity of mRNA 3 '-end formation in vivo were stimulated by the CTD (McCracken et al. 1997; Fong and Bentley 2001; Licatalosi et al. 2002; Ahn et al. 2004; Bird et al. 2004). This collection of work supported a model in which physical interaction with the CTD of elongating RNAP II helps recruit 3 '-end processing factors to the nascent RNA.

However, in yeast, a coupling with RNAP II is not essential for efficient processing (McNeil et al. 1998; Dower and Rosbash 2002). In addition, creatine phosphate alone cannot serve as a cofactor for cleavage in the yeast in vitro system (Chen and Moore 1992), although other nucleotides such as CTP or dATP are effective substitutes for ATP (Butler and Platt 1988). Butler and Platt also showed that 
cleavage depends on hydrolysis of the $\beta-\gamma$ bond of ATP. Moreover, RNA cross-linking of the $\mathrm{Cft} 2 / \mathrm{Ydh} 1$ subunit in the CF II subcomplex of CPF required ATP and a functional poly(A) site (Zhao et al. 1997). Overall, these studies suggested that NTP hydrolysis or NTP binding might be important for the cleavage step. Brr5 contains two possible P-loops in its $\mathrm{N}$ - and C-termini, but we have found that mutations in Brr5 that would have destroyed P-loop function in other ATP-binding proteins have no effect on cell viability, ruling out the idea that Brr5 binds or hydrolyzes ATP. Thus, while cleavage in yeast may need ATP as a cofactor, our findings indicate that its usage is unlikely to be mediated by Brr5. The recent discovery that the activity of a CPF-associated phosphatase, Glc7, is critical for execution of the poly(A) addition step (He and Moore 2005) suggests that ATP may be needed for a phosphorylation event.

\section{The role of the Brr5 C-terminus and its homolog, Syc1}

While the P-loop motif in the Brr5 C-terminus is not important, the last 30 amino acids and the T737 that lies in the vicinity of the P-loop homology are essential (Fig. 1C). In this report, we show that the C-terminus is critical for both cleavage and poly(A) addition. It is highly homologous to another CPF subunit, Sycl, and these two proteins interact with the CPF subunit Ptal, which is also needed for both steps of processing (Preker et al. 1997; Zhao et al. 1999b). However, we have found that cells lacking Syc1 give extract normal for in vitro mRNA 3'end processing, a result consistent with the finding that deletion of SYC1 does not affect cell viability. Nevertheless, the presence of Sycl exacerbates the growth defects of several processing mutants, and removal of Sycl by deletion of the gene rescues the cleavage defect of brr5-1 cells and partially relieves the defect in poly(A) addition. These observations suggest that Sycl works as a negative regulator of $3^{\prime}$-end processing, perhaps by competing with sites that interact with the Brr5 C-terminus.

There are two possible ways in which Sycl could execute such a function. First, Syc1, while not essential, may help to ensure the correct timing of different events in mRNA $3^{\prime}$ end formation. Certain mutations in CPF or CF I could create a situation in which Sycl cannot be as easily displaced from a part of CPF that needs to bind to the Cterminus of Brr5. Removal of Syc1 would now allow correct interaction of Brr5 so that it can function in cleavage and poly(A) addition. One such contact might take place through Ptal, which has been proposed to be a scaffold that helps to organize the $3^{\prime}$-end processing machinery (Takagaki and Manley 2000; Nedea et al. 2003).

Alternatively, Sycl might act as a checkpoint to slow processing down when there is a problem. Removal of Syc1 in some cleavage/polyadenylation mutants such as brr5-1, pta1-2, rna14-3, or rna15-2 could allow enough transcripts to be processed to restore growth at a previously restrictive temperature. With other mutants such as pta1-3, pfs $2-1$, and fip1-206, growth defects are more severe in the $s y c 1 \Delta$ background, with the most extreme case being pta1-3, in which sycls causes lethality. The pta1-3 mutant grows much more slowly than brr5-1 or pta1-2 at the permissive temperature (He et al. 2003), and perhaps loss of Sycl cannot be tolerated if the defect in processing is too severe. Similarly, $p f_{s} 2-1$ and fip1-206 are the most defective, yet still viable alleles that have been described for these two genes (Ohnacker et al. 2000; Helmling et al. 2001). While it is difficult to fully explain the genetic interactions without a better understanding of the architecture of the $3^{\prime}$-end-processing complex, these results nevertheless highlight the importance of Syc1 to optimal functioning of this machinery.

The Sycl of $S$. cerevisiae is highly conserved in other Saccharomyces species such as Saccharomyces bayanus, Saccharomyces kudriavzevii, Saccharomyces milatae, and Saccharomyces paradoxus, but it is not found in metazoans and is present in only one other fungus (Candida glabrata) of those whose genomes are available in the public protein databases. A similar situation exists for the C-terminus of Brr5, which is homologous to Syc1. It does not resemble the C-terminus of the metazoan orthologs, but similar domains are found in the Brr5 protein from Ashbya gossypii, Kluyveromyces lactis, Candida glabrata, Candida albicans, Debaryomyces hansenii, and Schizosaccharomyces pombe. Perhaps the fine-tuning of mRNA 3 '-end processing afforded by Sycl and the Brr5 C-terminus supports a more efficient response to a rapidly changing environment, and has led to the persistence of this domain in the genomes of these single-cell eukaryotes.

\section{The role of the $\beta$-CASP domain of Brr5}

Brr5 is a member of the $\beta$-CASP subfamily of the metallo$\beta$-lactamases, whose characterized members act on nucleic acids (Callebaut et al. 2002). The proteins in this family do not have a clearly identifiable match to the fifth of the five motifs that are found in other metallo- $\beta$-lactamase subfamilies and instead share in common three motifs designated motifs A, B, and C. Ryan et al. (2004) recently reported that mutations in conserved amino acids in two of these motifs (E209Q and H408F in motifs A and B) cause lethality in S. cerevisiae, underscoring the critical importance of this region. We also find that mutation of conserved histidines in the $\beta$-CASP B (H408A) or C motifs (H430D) is lethal (data not shown). Furthermore, we have mapped the mutation in the brr5-1 mutant strain to a single amino acid replacement of A407T, another conserved amino acid in the B-motif. Interestingly, the brr5-1 mutant is both cold-sensitive (Chanfreau et al. 1996) and heatsensitive for growth (this study). Extract from the brr5-1 strain is deficient in poly $(\mathrm{A})$ addition at $15^{\circ} \mathrm{C}$ (Chanfreau 
et al. 1996) and defective for cleavage and poly(A) addition at $30^{\circ} \mathrm{C}$ (Zhao et al. 1999b). Thus, the $\beta$-CASP domain may function in both processing steps. Alternatively, if Brr5 is the mRNA $3^{\prime}$-end nuclease, this region could be important in positioning RNA in the active site of the nuclease. In this model, the brr5-1 mutant could negatively impact on poly(A) addition by interacting nonproductively with RNA substrate in a way that prevented poly $(\mathrm{A})$ polymerase from accessing the $3^{\prime}$-end of precleaved RNA.

\section{Summary}

Our results on the function of Brr5 and Syc1 extend our understanding of the organization of the yeast mRNA $3^{\prime}$ end processing machinery and the function of its various parts. Previous research indicates that CFI and CPF are both important in directing the processing machinery to the correct site on mRNA precursor. This is accomplished by recognition of signal sequences that reside upstream of the cleavage site by CF I (Kessler et al. 1997; Gross and Moore 2001), interaction with sequences flanking the poly(A) site by CPF (Barabino et al. 2000; Dichtl and Keller 2001; Dichtl et al. 2002b; Tacahashi et al. 2003), and numerous potential cross-factor interactions between CF I and CPF (Preker et al. 1995; Ohnacker et al. 2000; He et al.
2003; Kyburz et al. 2003; Cheng et al. 2004; Dichtl et al. 2004). Our current study lends support to a model in which the action of Brr5, through its $\beta$-CASP domain and its Cterminus, affects both the endonuclease and poly(A) polymerase activities of the processing complex. These activities are regulated by other subunits of CPF such as Sycl as the reaction proceeds from complex assembly, cleavage, poly(A) addition, termination of polyadenylation, and release from the final product.

\section{MATERIALS AND METHODS}

\section{Yeast strains and genetic analysis}

The yeast strains and sources used in this study are given in Table 1 . We introduced mutations into the BRR5 coding sequence by PCRbased mutagenesis using Deep Vent DNA polymerase (NEB) and primers containing the desired mutation, a new restriction site that does not affect the amino acid sequences and a unique restriction site for cloning. The wild-type Brr5 sequence, cloned into pET16b as described by Tacahashi et al. (2003), was used as a template, and the relevant part of the wild-type Brr5 in this plasmid was then replaced with the amplified fragment. Mutations were confirmed by digestion with restriction enzymes followed by sequencing. The mutated brr5 sequence was then transferred into YCP50 (URA3) or YCPlac111 (LEU2) plasmids for expression in

TABLE 1. Saccharomyces cerevisiae strains used in this study

\begin{tabular}{|c|c|c|}
\hline Name & Genotype & Source \\
\hline FY23 & MATa, ura3-52, leu2 $\Delta 1, \operatorname{trp} 1 \Delta 63$ & Winston et al. 1995 \\
\hline YAZ212 & 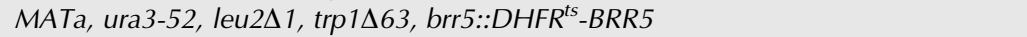 & This study \\
\hline YAZ216 & 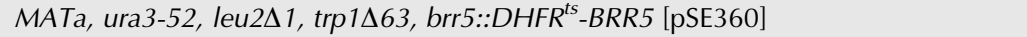 & This study \\
\hline YAZ220 & 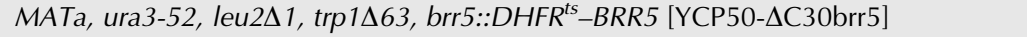 & This study \\
\hline CEN PK2 & MATa, leu2-3, 112, ura3-52, trp1-289, his3- $\Delta 1$ & EUROSCARF \\
\hline YSN399 & MAT $\alpha$, ura3-52 his3- $\Delta 200$, ade12-100o, leu2- $\Delta 1$, lys2-801a, brr5-1 & Chanfreau et al. 1996 \\
\hline YSN378 & 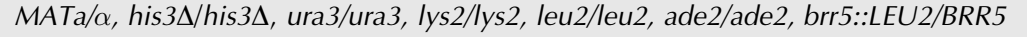 & Chanfreau et al. 1996 \\
\hline YOM7 & YSN378 haploid, pSE360 & Chanfreau et al. 1996 \\
\hline BY4743 & $\begin{array}{l}\text { MATa/ } \alpha \text {, his } 3 \Delta 1 / \text { his } 3 \Delta 1 \text {, ura3 } \Delta 0 / \text { ura } 3 \Delta 0 \text {, lys } 2 \Delta 0 / L Y S 2, \text { leu2 } \Delta 0 / \text { leu2 } 20 \text {, met15/MET, } \\
\quad \text { brr5::kanMX/BRR5 }\end{array}$ & ATCC 201390 \\
\hline HKY1 & Same as CEN PK2 with syc1::kanMX & This study \\
\hline YAZ142 & brr5-1/syc1 1 derived from mating YSN399 and HKY1 & This study \\
\hline MO17 & ura3-1, trp1, ade2-1, leu2-3, 112, his3-11, 15, pfs2::TRP1, pFL36-pfs2-1 & Ohnacker et al. 2000 \\
\hline YAZ161 & pfs2-1/syc1 $1 \Delta$ derived from mating MO17 and HKY1 & This study \\
\hline UR3148 & MAT $\alpha$, ade1/ade2, lys2, gal1, ura3-52, pap1-1 & Patel and Butler 1992 \\
\hline YAZ167 & pap1-1/syc1 1 derived from mating UR3148 and HKY1 & This study \\
\hline fip1-206 & Mato, leu2-3, 112, ura3-52, trp1, his4, fip1::LEU2, [p314/fip1-206] & Helmling et al. 2001 \\
\hline YAZ165 & fip1-206/syc1 1 derived from mating FY1284 and HKY1 & This study \\
\hline FY1284 & MATa pta1-2 ura3-52 ade8 his4-917 & Madison and Winston 1997 \\
\hline YAZ121 & pta1-2/syc1 1 derived from mating YSN399 and HKY1 & This study \\
\hline $\mathrm{XH} 15$ & MATa ura3-52 leu21 trp163 his3200 pta1::TRP1 [YCpLEU2-pta1-3] & He et al. 2003 \\
\hline YAZ184 & pta1-3/syc1 1 [YCP50-PTA1] & This study \\
\hline W303 & ade2,-1 his3-11, 15, trp1-1, ura3-1, leu2-3, 112 can1-100 & F. Lacroute \\
\hline THJY83 & W303, but $M A T \alpha$, rna14-3 & F. Lacroute \\
\hline THJY84 & W303, but $M A T \alpha$, rna15-2 & F. Lacroute \\
\hline THJY977 & MATa, ade2-1, ura3-1, his3-11,15, leu2-3, 112, trp1-1, can1-100, SYC1::HIS3 & This study \\
\hline THJY978 & MAT $\alpha$, ade2-1, ura3-1, his3-11,15, leu2-3, 112, trp1-1, can1-100, SYC1::HIS3 & This study \\
\hline THJY1189 & MAT?, ade2-1, leu2, his3-11,15, rna14-3, SYC1::HIS3 & This study \\
\hline THJY1193 & MAT ?, ade2-1, leu2, his3-11,15, rna15-2, SYC1::HIS3 & This study \\
\hline
\end{tabular}


yeast. Viability and phenotype of Brr5 truncations were determined by spore analysis of YSN378 diploid cells carrying a deletion of one chromosomal copy of BRR5 (Chanfreau et al. 1996) transformed with a YCP50 plasmid (URA3) containing the mutant brr5 sequence. Point mutations of BRR5 were analyzed using plasmid shuffle and counterselection on medium containing 5-fluoroorotic acid (5-FOA) to replace the pSE360 (BRR5, URA3) plasmid (Noble and Guthrie 1996) with YCplac111 containing mutant brr5.

The deletion of SYC1 in CEN-PK2 cells was accomplished by integration of the kanMX6 module as described previously (Longtine et al. 1998) to give the strain HKY1. The genetic interactions of the $s y c 1 \Delta$ mutant with various RNA processing mutants were performed at different temperatures as indicated in figure legends using haploids derived by mating the HKY1 strain with those mutants, sporulating and dissecting tetrads, and selection of double mutants using selective medium, cell viability, and temperature sensitivity.

\section{In vivo depletion of Brr5}

To create the Degron-brr5 strain, the SspI/PvuII fragment of the pPW66R plasmid (Dohmen et al. 1994) containing the CUP1DHFR sequence was ligated to pUG6 (Guldener et al. 1996) linearized with PvuII. A 630-nt PCR fragment of BRR5 encoding the N-terminus was then inserted into the KpnI/MscI sites of that plasmid. The resulting plasmid was linearized with Bsu36I and transformed into FY23 yeast cells, and recombinants were selected on YPD medium containing $200 \mu \mathrm{g} / \mathrm{mL} \mathrm{G418,} \mathrm{followed} \mathrm{by} \mathrm{tem-}$ perature-sensitivity screening and confirmation that the thermosensitive growth could be rescued by plasmid containing BRR5. The expression of Degron-brr5 at permissive temperature $\left(24^{\circ} \mathrm{C}\right)$ and its degradation at nonpermissive temperature $\left(37^{\circ} \mathrm{C}\right)$ as well as lack of wild-type Brr5 protein was confirmed by Western blot analysis using rabbit polyclonal antibody specific to Brr5.

\section{In vitro processing and transcription run-on assays}

Extract preparation and processing assays were performed as described previously ( $\mathrm{He}$ and Moore 2005). Equal amounts of protein $(30 \mu \mathrm{g})$ were used for reactions and corresponding Western blots. Reaction products were separated on $6 \%$ polyacrylamide gels containing $8 \mathrm{M}$ urea and visualized and quantitated by PhosphorImager analysis. Quantitation was performed by measuring the amount of radioactivity in the precursor and product bunds in each lane and calculating the percentage of processed RNA. The efficiency of processing for each extract was determined by averaging the values from three separate experiments, and this average was used to calculate the fold-change in processing at $37^{\circ} \mathrm{C}$ relative to that at $24^{\circ} \mathrm{C}$.

For preparation of extract from Degron-brr5 strains, cells were grown in $1 \mathrm{~L}$ of selective media at $24^{\circ} \mathrm{C}$ to an $\mathrm{OD}_{600}$ of 1 , split in half, and collected by centrifugation. Each half was resuspended in 50 $\mathrm{mL}$ of $24^{\circ} \mathrm{C}$ (control) or preheated $\left(37^{\circ} \mathrm{C}\right)$ media, and growth was continued at the permissive or nonpermissive temperatures, respectively, for an additional $90 \mathrm{~min}$. After centrifugation, cells were resuspended in $30 \mathrm{~mL}$ of $1 \mathrm{M}$ sorbitol, $50 \mathrm{mM}$ Tris- $\mathrm{HCl}$ (pH 7.9), $10 \mathrm{mM}$ $\mathrm{MgCl}_{2}$, and $10 \%$ glycerol, and frozen until extracts were made.

Transcription run-on assays were performed using the G-less cassette method (Steinmetz and Brow 2003).

\section{Analysis of protein/protein interactions}

For GST pull-downs, Brr5, Syc1, and Rna15 were in vitro translated using the TNT T7 Coupled Reticulocyte Lysate System (Promega) and labeled with $\left[{ }^{35} \mathrm{~S}\right]$ methionine according to the manufacturer's instructions. To prepare the beads, $20 \mu \mathrm{L}$ of a $50 \%$ slurry of glutathione Sepharose 4B (Pharmacia) was incubated in $100 \mu \mathrm{L}$ of buffer IP-150 $(150 \mathrm{mM} \mathrm{KCl}, 20 \mathrm{mM}$ Tris at $\mathrm{pH}$ $8,0.1 \% \mathrm{NP}-40)$. After incubation for $1 \mathrm{~h}$ at $4^{\circ} \mathrm{C}$, a mixture of 500 ng of purified GST or GST-Ptal (He et al. 2003) and in vitro translated Brr5 or Syc1 was added to the beads. This mixture was incubated for $2 \mathrm{~h}$ at $4^{\circ} \mathrm{C}$, and beads were washed with $1 \mathrm{~mL}$ of IP150 three times. The bound proteins were eluted in $50 \mathrm{mM}$ glutathione and applied onto a 10\% SDS-polyacrylamide gel. The resolved proteins were detected by autoradiography.

For coimmunoprecipitation, yeast whole-cell extracts $(150 \mu \mathrm{g})$ were incubated with antibody against Brr5 bound to anti-rabbit IgG agarose (Sigma) at $4^{\circ} \mathrm{C}$ for $2-4 \mathrm{~h}$ in $200 \mu \mathrm{L}$ of buffer IP-150 (He et al. 2003). Beads were washed four times with $300 \mu \mathrm{L}$ of buffer IP-150. The bound proteins were eluted with $20 \mu \mathrm{L}$ of SDS sample buffer, and analyzed on an SDS-10\% polyacrylamide gel. Western blotting was performed according to standard procedures.

For two-hybrid assays, plasmid pGBD-PTA1 was constructed by insertion of the PTA1 open reading frame into vector pGBD-C2 (James et al. 1996). The yeast two-hybrid selection strain PJ69-4A was transformed with pGBD-PTA1 and pGAD plasmid library $\mathrm{C} 1$, C2, or C3 (James et al. 1996) containing fusions of GAD to yeast genomic DNA fragments. Transformants were selected on medium lacking leucine, tryptophan, and histidine in the presence of 2 $\mathrm{mM} 3$-aminotriazole. Candidates were then tested for activation of the LACZ reporter dependent on the presence of the pGBD-PTA1 plasmid, and positive candidates were then sequenced.

\section{ACKNOWLEDGMENTS}

This work was supported by NIH grant GM041752 to C.M. and by the Danish National Research and the Novo Nordisk Foundations to T.H.J.

Received October 18, 2005; accepted November 29, 2005.

\section{REFERENCES}

Ahn, S.H., Kim, M., and Buratowski, S. 2004. Phosphorylation of serine 2 within the RNA polymerase II C-terminal domain couples transcription and $3^{\prime}$ end processing. Mol. Cell 13: 67-76.

Aravind, L. 1999. An evolutionary classification of the metallo- $\beta$ lactamase fold proteins. In Silico Biol. 1: 69-91.

Barabino, S.M., Ohnacker, M., and Keller, W. 2000. Distinct roles of two Yth1p domains in $3^{\prime}$-end cleavage and polyadenylation of yeast pre-mRNAs. EMBO J. 19: 3778-3787.

Bird, G., Zorio, D.A., and Bentley, D. L. 2004. RNA polymerase II carboxy-terminal domain phosphorylation is required for cotranscriptional pre-mRNA splicing and 3 '-end formation. Mol. Cell. Biol. 24: 8963-8969.

Birse, C.E., Minvielle-Sebastia, L., Lee, B.A., Keller, W., and Proudfoot, N.J. 1998. Coupling termination of transcription to messenger RNA maturation in yeast. Science 280: 298-301.

Butler, J.S. and Platt, T. 1988. RNA processing generates the mature $3^{\prime}$ end of yeast CYC1 messenger RNA in vitro. Science 242: 12701274. 
Callebaut, I., Moshous, D., Mornon, J.P., and de Villartay, J.P. 2002. Metallo- $\beta$-lactamase fold within nucleic acids processing enzymes: The $\beta$-CASP family. Nucleic Acids Res. 30: 3592-3601.

Chanfreau, G., Noble, S.M., and Guthrie, C. 1996. Essential yeast protein with unexpected similarity to subunits of mammalian cleavage and polyadenylation specificity factor (CPSF). Science 274: $1511-1514$.

Chen, J. and Moore, C. 1992. Separation of factors required for cleavage and polyadenylation of yeast pre-mRNA. Mol. Cell. Biol. 12: $3470-3481$.

Cheng, H., He, X., and Moore, C. 2004. The essential WD repeat protein Swd2 has dual functions in RNA polymerase II transcription termination and lysine 4 methylation of histone H3. Mol. Cell. Biol. 24: 2932-2943.

Daiyasu, H., Osaka, K., Ishino, Y., and Toh, H. 2001. Expansion of the zinc metallo-hydrolase family of the $\beta$-lactamase fold. FEBS Lett. 503: 1-6.

Dichtl, B. and Keller, W. 2001. Recognition of polyadenylation sites in yeast pre-mRNAs by cleavage and polyadenylation factor. EMBO J. 20: 3197-3209.

Dichtl, B., Blank, D., Ohnacker, M., Friedlein, A., Roeder, D., Langen, H., and Keller, W. 2002a. A role for SSU72 in balancing RNA Polymerase II transcription elongation and termination. Mol. Cell 10: 1139-1150.

Dichtl, B., Blank, D., Sadowski, M., Hubner, W., Weiser, S., and Keller, W. 2002b. Yhhlp/Cftlp directly links poly(A) site recognition and RNA polymerase II transcription termination. EMBO J. 21: 4125-4135.

Dichtl, B., Aasland, R., and Keller, W. 2004. Functions for S. cerevisiae Swd2p in $3^{\prime}$ end formation of specific mRNAs and snoRNAs and global histone 3 lysine 4 methylation. RNA 10: 965-977.

Dohmen, R.J., Wu, P., and Varshavsky, A. 1994. Heat-inducible degron: A method for constructing temperature-sensitive mutants. Science 263: 1273-1276.

Dominski, Z., Yang, X.C., and Marzluff, W.F. 2005. The polyadenylation factor CPSF-73 is involved in histone-pre-mRNA processing. Cell 123: $37-48$.

Dower, K. and Rosbash, M. 2002. T7 RNA polymerase-directed transcripts are processed in yeast and link $3^{\prime}$ end formation to mRNA nuclear export. RNA 8: 686-697.

Fong, N. and Bentley, D.L. 2001. Capping, splicing, and 3' processing are independently stimulated by RNA polymerase II: Different functions for different segments of the CTD. Genes \& Dev. 15: $1783-1795$.

Gavin, A.C., Bosche, M., Krause, R., Grandi, P., Marzioch, M., Bauer, A., Schultz, J., Rick, J.M., Michon, A.M., Cruciat, C.M., et al. 2002. Functional organization of the yeast proteome by systematic analysis of protein complexes. Nature 415: 141-147.

Gross, S. and Moore, C.L. 2001. Rna15 interaction with the A-rich yeast polyadenylation signal is an essential step in mRNA $3^{\prime}$-end formation. Mol. Cell. Biol. 21: 8045-8055.

Guldener, U., Heck, S., Fielder, T., Beinhauer, J., and Hegemann, J.H. 1996. A new efficient gene disruption cassette for repeated use in budding yeast. Nucleic Acids Res. 24: 2519-2524.

$\mathrm{He}, \mathrm{X}$. and Moore, C. 2005. Regulation of yeast mRNA $3^{\prime}$ end processing by phosphorylation. Mol. Cell 19: 619-629.

He, X., Khan, A.U., Cheng, H., Pappas Jr., D.L., Hampsey, M., and Moore, C.L. 2003. Functional interactions between the transcription and mRNA $3^{\prime}$ end processing machineries mediated by Ssu72 and Subl. Genes \& Dev. 17: 1030-1042.

Helmling, S., Zhelkovsky, A., and Moore, C.L. 2001. Fip1 regulates the activity of poly(A) polymerase through multiple interactions. Mol. Cell. Biol. 21: 2026-2037.

Hirose, Y. and Manley, J.L. 1998. RNA polymerase II is an essential mRNA polyadenylation factor. Nature 395: 93-96.

James, P., Halladay, J., and Craig, E.A. 1996. Genomic libraries and a host strain designed for highly efficient two-hybrid selection in yeast. Genetics 144: 1425-1436.

Jenny, A., Minvielle-Sebastia, L., Preker, P.J., and Keller, W. 1996. Sequence similarity between the 73-kilodalton protein of mamma- lian CPSF and a subunit of yeast Polyadenylation Factor I. Science 274: 1514-1517.

Kessler, M.M., Henry, M.F., Shen, E., Zhao, J., Gross, S., Silver, P.A., and Moore, C.L. 1997. Hrp1, a sequence-specific RNA-binding protein that shuttles between the nucleus and the cytoplasm, is required for mRNA $3^{\prime}$-end formation in yeast. Genes \& Dev. 11: 2545-2556.

Kolev, N.G. and Steitz, J.A. 2005. Symplekin and multiple other polyadenylation factors participate in $3^{\prime}$-end maturation of histone mRNAs. Genes \& Dev. 19: 2583-2589.

Kyburz, A., Sadowski, M., Dichtl, B., and Keller, W. 2003. The role of the yeast cleavage and polyadenylation factor subunit Ydh1p/Cft2p in pre-mRNA 3'-end formation. Nucleic Acids Res. 31: 3936-3945.

Li, X., Hejna, J., and Moses, R.E. 2005. The yeast Snm1 protein is a DNA 5'-exonuclease. DNA Repair (Amst) 4: 163-170.

Licatalosi, D.D., Geiger, G., Minet, M., Schroeder, S., Cilli, K., McNeil, J.B., and Bentley, D.L. 2002. Functional interaction of yeast premRNA 3' end processing factors with RNA polymerase II. Mol. Cell 9: 1101-1111.

Longtine, M.S., McKenzie III, A., Demarini, D.J., Shah, N.G., Wach, A., Brachat, A., Philippsen, P., and Pringle, J.R. 1998. Additional modules for versatile and economical PCR-based gene deletion and modification in Saccharomyces cerevisiae. Yeast 14: 953-961.

Ma, Y., Pannicke, U., Schwarz, K., and Lieber, M.R. 2002. Hairpin opening and overhang processing by an Artemis/DNA-dependent protein kinase complex in nonhomologous end joining and $\mathrm{V}(\mathrm{D}) \mathrm{J}$ recombination. Cell 108: 781-794.

Madison, J.M. and Winston, F. 1997. Evidence that Spt3 functionally interacts with Mot1, TFIIA, and TATA-binding protein to confer promoter-specific transcriptional control in Saccharomyces cerevisiae. Mol. Cell. Biol. 17: 287-295.

McCracken, S., Fong, N., Yankulov, K., Ballantyne, S., Pan, G., Greenblatt, J., Patterson, S.D., Wickens, M., and Bentley, D.L. 1997. The C-terminal domain of RNA polymerase II couples mRNA processing to transcription. Nature 385: 357-361.

McNeil, J.B., Agah, H., and Bentley, D. 1998. Activated transcription independent of the RNA polymerase II holoenzyme in budding yeast. Genes \& Dev. 12: 2510-2521.

Nedea, E., He, S., Kim, M., Pootoolal, J., Zhong, G., Canadien, V., Hughes, T., Buratowski, S., Moore, C., and Greenblatt, J. 2003. Organization and function of APT, a sub-complex of the yeast Cleavage and Polyadenylation Factor involved in the formation of snoRNA 3' ends. J. Biol. Chem. 278: 33000-33010.

Noble, S.M. and Guthrie, C. 1996. Identification of novel genes required for yeast pre-mRNA splicing by means of cold-sensitive mutations. Genetics 143: 67-80.

Ohnacker, M., Barabino, S.M., Preker, P.J., and Keller, W. 2000. The WD-repeat protein $\mathrm{pfs} 2 \mathrm{p}$ bridges two essential factors within the yeast pre-mRNA $3^{\prime}$-end-processing complex. EMBO J. 19: 37-47.

Patel, D. and Butler, J.S. 1992. Conditional defect in mRNA $3^{\prime}$ end processing caused by a mutation in the gene for poly(A) polymerase. Mol. Cell. Biol. 12: 3297-3304.

Preker, P.J., Lingner, J., Minvielle-Sebastia, L., and Keller, W. 1995. The FIP1 gene encodes a component of a yeast pre-mRNA polyadenylation factor that directly interacts with poly(A) polymerase. Cell 81: 379-389.

Preker, P.J., Ohnacker, M., Minvielle-Sebastia, L., and Keller, W. 1997. A multisubunit $3^{\prime}$ end processing factor from yeast containing poly(A) polymerase and homologues of the subunits of mammalian cleavage and polyadenylation specificity factor. EMBO J. 16: 4727-4737.

Ryan, K., Murthy, K.G., Kaneko, S., and Manley, J.L. 2002. Requirements of the RNA polymerase II C-terminal domain for reconstituting pre-mRNA 3' cleavage. Mol. Cell. Biol. 22: 1684-1692.

Ryan, K., Calvo, O., and Manley, J.L. 2004. Evidence that polyadenylation factor CPSF-73 is the mRNA $3^{\prime}$ processing endonuclease. RNA 10: $565-573$.

Sadowski, M., Dichtl, B., Hubner, W., and Keller, W. 2003. Independent functions of yeast Pcfl1 $\mathrm{p}$ in pre-mRNA $3^{\prime}$ end processing and in transcription termination. EMBO J. 22: 2167-2177. 
Saraste, M., Sibbald, P.R., and Wittinghofer, A. 1990. The P-loop-A common motif in ATP- and GTP-binding proteins. Trends Biochem. Sci. 15: 430-434.

Schiffer, S., Rosch, S., and Marchfelder, A. 2002. Assigning a function to a conserved group of proteins: The tRNA $3^{\prime}$-processing enzymes. EMBO J. 21: 2769-2777.

Steinmetz, E. and Brow, D. 2003. Ssu72 protein mediates both poly(A) coupled and poly(A)-independent termination of RNA polymerase II transcription. Mol. Cell. Biol. 23: 6339-6349.

Tacahashi, Y., Helmling, S., and Moore, C.L. 2003. Functional dissection of the zinc finger and flanking domains of the Yth1 cleavage/polyadenylation factor. Nucleic Acids Res. 31: 17441752.

Takagaki, Y. and Manley, J.L. 2000. Complex protein interactions within the human polyadenylation machinery identify a novel component. Mol. Cell. Biol. 20: 1515-1525.
Winston, F., Dollard, C., and Ricupero-Hovasse, S.L. 1995. Construction of a set of convenient Saccharomyces cerevisiae strains that are isogenic to S288C. Yeast 11: 53-55.

Zhao, J., Kessler, M.M., and Moore, C.L. 1997. Cleavage factor II of Saccharomyces cerevisiae contains homologues to subunits of the mammalian Cleavage/polyadenylation specificity factor and exhibits sequence-specific, ATP-dependent interaction with precursor RNA. J. Biol. Chem. 272: 10831-10838.

Zhao, J., Hyman, L., and Moore, C. 1999a. Formation of mRNA 3' ends in eukaryotes: Mechanism, regulation, and interrelationships with other steps in mRNA synthesis. Microbiol. Mol. Biol. Rev. 63: 405-445.

Zhao, J., Kessler, M., Helmling, S., O’Connor, J.P., and Moore, C. 1999b. Ptal, a component of yeast CF II, is required for both cleavage and poly(A) addition of mRNA precursor. Mol. Cell. Biol. 19: 7733-7740. 

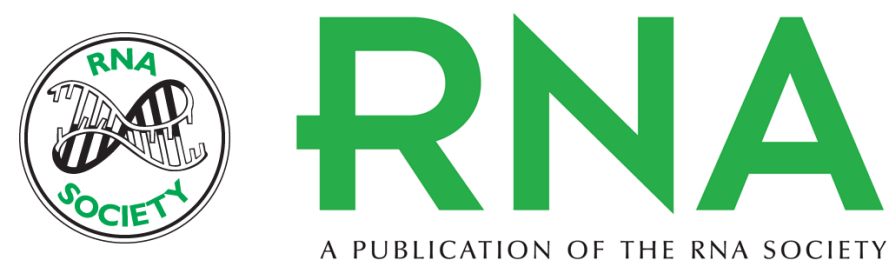

\title{
The role of the Brr5/Ysh1 C-terminal domain and its homolog Syc1 in mRNA 3 '-end processing in Saccharomyces cerevisiae
}

\author{
ALEXANDER ZHELKOVSKY, YOKO TACAHASHI, TOMMY NASSER, et al.
}

RNA 2006 12: 435-445

References This article cites 56 articles, 36 of which can be accessed free at:

http://rnajournal.cshlp.org/content/12/3/435.full.html\#ref-list-1

License

Email Alerting Receive free email alerts when new articles cite this article - sign up in the box at the Service top right corner of the article or click here. 